\title{
Femur başı avasküler nekrozunda kor dekompresyon ve kök hücre tedavisi
}

\section{Core decompression and stem cell therapy for femoral head avascular necrosis}

\author{
Yasin Güler ${ }^{1}$, Süleyman Semih Dedeoğlu², Bilal Bostancı ${ }^{1}$ \\ ${ }^{1}$ İstanbul Medipol Üniversitesi Tıp Fakültesi, Ortopedi ve Travmatoloji Anabilim Dalı, İstanbul \\ ${ }^{2}$ İstanbul S.B.Ü. Okmeydanı E.A.H., Prof. Dr. Cemil Taşçıŏlu Şehir Hastanesi, Ortopedi ve Travmatoloji Anabilim Dalı, İstanbul
}

Femur başı avasküler nekrozu (femur başı osteonekrozu, FBO); vasküler dolaşımın çeşitli sebeplere bağlı olarak bozulması sonucunda kemik dokunun canlı hücrelerinin ölümü ile seyreden patolojik bir süreçtir. Osteonekroz etiyolojisi halen belirsiz olmakla birlikte çok geniştir. Alkolizm, aşırı steroid kullanımı, travma, orak hücreli anemi etiyolojide sık karşılaşılan nedenler arasındadır. Bunların yanında yağ embolisi, intraosseöz basıncın artışı ve trabeküler kemiğin mikrokırığı gibi patofizyolojik mekanizmaların etiyolojide rol oynadığı öne sürülmüştür. Nekrotik süreci engellemek zor olduğundan, hastalığın tedavisi oldukça güç ve sorunludur. Femur başı osteonekrozu olan hastalarda tipik olarak kemik iliğinde yağ infiltrasyonu ve az sayıda kök hücre bulunur. Mezenkimal kök hücreler (MKH’ler) ortopedide birçok rejeneratif tedavi stratejisi için sıklıkla tercih edilmektedir. FBO'da uygulanan tedavi seçeneklerinden birisi de kor dekompresyon ve kök hücre enjeksiyonudur. Bu tedavi metodunun amacı intraosseöz basıncı azaltarak femur başına kan akışını iyileştirmek, iliak krestten elde edilen kök hücrelerin otolog transferi ile yeni kemik oluşumunu uyarmak ve böylece eklem artrozu oluşma ihtimalini azaltarak veya engelleyerek eklemi korumaktır.

Anahtar sözcülkler: avasküler nekroz; kemik iliği; osteonekroz; alkolizm; kemik dokusu; patolojik süreç; kor dekompresyon; kök hücre
Femoral head avascular necrosis (Femoral head ostenecrosis, $\mathrm{FHO}$ ); It is a pathological process that progresses with the death of living cells of bone tissue as a result of vascular circulation being disrupted due to various reasons. Although the etiology of osteonecrosis is still uncertain, it is very broad. Alcoholism, excessive steroid use, trauma, sickle cell anemia, are among the common etiological causes. In addition, pathophysiological mechanisms such as fat embolism, increased intraosseous pressure and microfracture of the trabecular bone have been suggested to play a role in the etiology. Treatment of the disease is quite difficult and problematic, since it is difficult to prevent the necrotic process. Patients with osteonecrosis of the femoral head typically have bone marrow fat infiltration and few stem cells. Mesenchymal stem cells (MDGs) are often preferred for many regenerative treatment strategies in orthopedics. One of the treatment options applied in $\mathrm{FBO}$ is core decompression and stem cell injection. The purpose of this treatment method is to improve blood flow per femur by reducing intraosseous pressure, to stimulate new bone formation by autologous transfer of stem cells obtained from iliac crest, thereby protecting the joint by reducing or preventing the possibility of joint arthrosis.

Key words: avascular necrosis; bone marrow; osteonecrosis; alcoholism; bone tissue; pathological process; core decompression; stem cells
F emur başı avasküler nekrozu (Femur başı osteonekrozu, FBO), patogenezi halen belirsiz olan geniş etiyolojiye sahip bir hastalıktır. ${ }^{[1]}$ Glukokortikoid kullanımı ve alkolizm, bu hastalık için en çok bilinen risk faktörleri arasındadır. Yağ embolisi, intraosseöz basıncın artışı ve trabeküler kemiğin mikrokırı̆̆ı gibi patofizyolojik mekanizmalar etiyolojide öne sürülmüştür. ${ }^{[2]}$
FBO'da uygulanan kor dekompresyon, intraosseöz basıncı azaltarak femur başına kan akışını iyileştirmeyi ve böylece total kalça artroplastisini (TKA) potansiyel olarak geciktirmeyi veya önlemeyi amaçlayan eklem koruyucu bir cerrahi tekniktir. Fizyolojik olarak, bu prosedürün amacı, yeni kemik oluşumunu uyarmak ve femur başının kemik iliğini yeni kök hücreler ile değiştirmektir. Çünkü avasküler nekrozlu (AVN'li)

- Illetişim adresi: Dr. Yasin Güler, TEM Avrupa Otoyolu Göztepe Çıkışı No: 1, 34214 Bağcılar, İstanbul

Tel: 0533 - 8132833 e-posta: yaskokacar@hotmail.com

- Geliș tarihi: 8 Eylül 2020 Kabul tarihi: 23 Eylül 2020 
hastaların nekroz alanlarında azalmış kök hücre popülasyonuna sahip oldukları gösterilmiştir. ${ }^{[3]}$ Geleneksel kor dekompresyon, femur başındaki osteonekrotik lezyondan 8 ila 10 mm'lik bir çekirdek çıkarmak için bir oyucu kullanılarak gerçekleştirilir. Eklem yüzünü penetre etmekten kaçınılmalıdır. ${ }^{[4]}$

Mezenkimal kök hücreler (MKH’ler) ortopedi ve travmatoloji alanında birçok rejeneratif tedavi stratejisi için sıklıkla tercih edilmektedir. ${ }^{[5]}$ Femur başı osteonekrozu olan hastalarda tipik olarak kemik iliğinde yağ infiltrasyonu ve az sayıda kök hücre bulunur. ${ }^{[6]}$ Dolayısıyla, kor dekompresyon ile birlikte tipik olarak iliak krestten (kristadan) elde edilen kök hücrelerin otolog transferinin kök hücrelerin rejenerasyonunu teşvik edeceği ve femur başındaki vaskülariteyi artıracağı düşünülebilir.

Son iki dekatta, iliak kanattan otolog konsantre kemik iliği ile augmente edilen kor dekompresyonun erken evre AVN'de sonuçları iyileştirmede başarılı olduğunu gösteren bir dizi çalışma yapılmıştır. ${ }^{[7-9]}$ Buna paralel hastalığın radyografik olarak ilerlemesinin durduğu ve hastaların büyük çoğunluğunda TKA'ya gidişin durduğunu gösteren çok sayıda çalışma vardır. ${ }^{[7-11]}$

MKH'nin kilit rolü, kondrositler ve osteositler gibi çeşitli bağ dokusu hücre tiplerine farklılaşma potansiyellerinden kaynaklanmaktadır. Öte yandan, MKH'nin veya $M K H^{\prime}$ 'nin parakrin faktörlerinin çeşitli düzenleyici özellikleri tanımlanmıştır. Bunlar arasında konakçı hücrelerde rejeneratif farklılaşma süreçleri için immunomodülatör, antiapoptotik ve koordinatif fonksiyonlar bulunur. ${ }^{[12]}$

Kemik iliği aspirasyon konsantresi, büyüme faktörleri ve mezenkimal kök hücre içeren biyolojik tedavidir. Mezenkimal kök hücrelerin kendilerini yenileme ve multipotent farklılaşma özellikleri (plastisite) vardır. ${ }^{[13-15]}$ Birçok yazar 60-120 mL kemik iliği aspirasyonu önermiştir. Santrifüj işleminden sonra da lezyon bölgesine 6-15 mL aralığında enjeksiyon öneren çalışmalar mevcuttur $^{[16-19]} ; 60 \mathrm{~mL}$ kemik iliği aspiratının (KiA) santrifüj edilmesinden standart 4 ila $6 \mathrm{~mL}$ kemik iliği aspirasyon konsantresi üretilir ve yaklaşık 40,000 MKH içerir. ${ }^{[20,21]}$

\section{CERRAHI TEKNIK}

Kemik iliği aspirasyonu ile santrifüj sonrasında $\mathrm{MKH}$ elde edilmesi ve femur başı kor dekompresyonu işlemleri aynı cerrahi sırasında uygulanır. Lomber (spinal) veya genel anestezi altında radyolusen masada supin (sırtüstü) yatırılan hastaya steril cerrahi hazırlık işlemleri yapıldıktan sonra iliak kristalardan birinin (veya her ikisinin) üzerine 2-3 mm'lik küçük bir kesi yapılır. İnsizyon, anterior-superior iliak spinaya doğru (SIAS) proksimal-lateral uzanır ve aspirasyonun yörüngesi supra-asetabular alana doğru hedeflenir. Antikoagülan kaplı trokarlar iliumun iki tabakası arasında ilerletilir. ${ }^{[18]}$

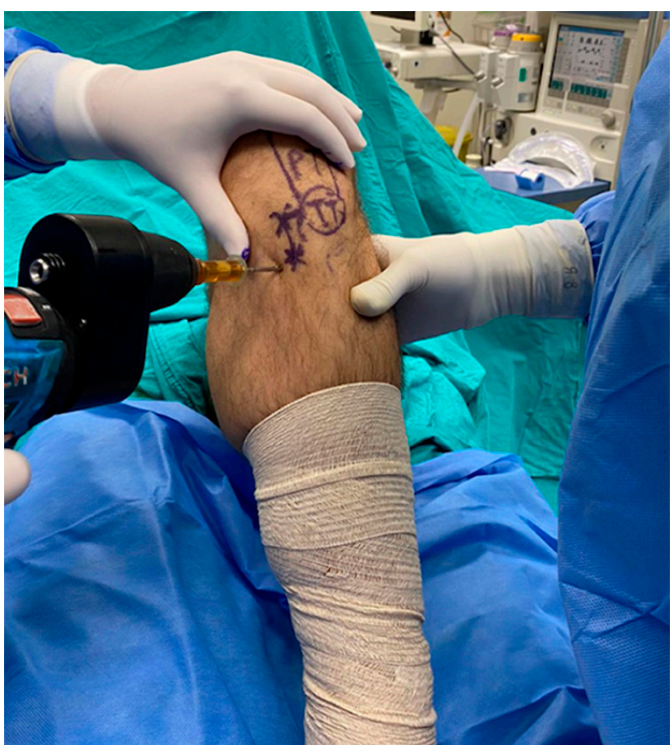

Şekil 1. Yaklaşık $45^{\circ}$ açıyla oyucuya takılan trokar medulla içerisine gönderilir.

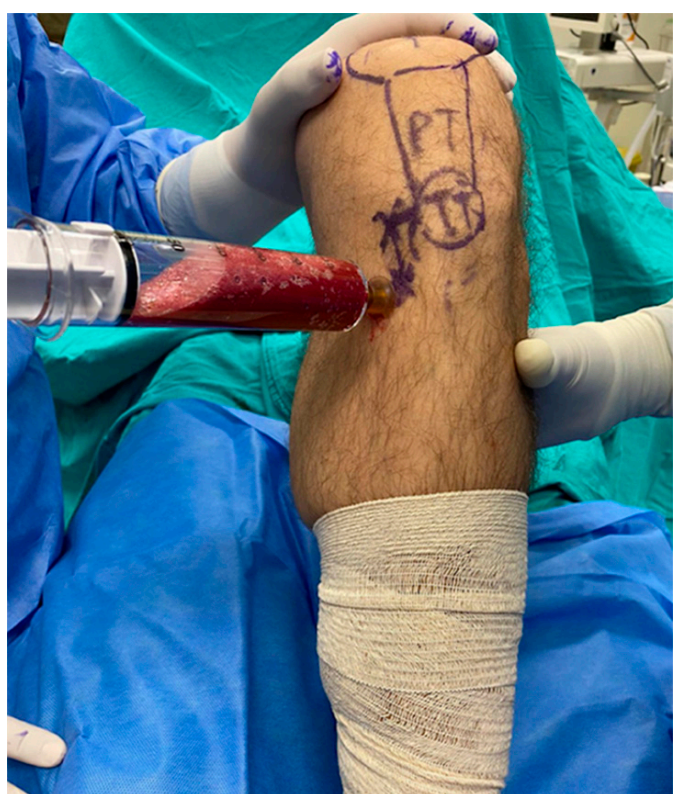

Şekil 2. Yaklaşık $60 \mathrm{cc}$ otolog kemik iliği gönderilen kanüllü oyucuya kilitlenen özel şırıngayla aspire edilir.

Kemik iliği aspirasyonunun kolaylıkla yapılabileceği ve bizim de tercih ettiğimiz bir diğer bölge tibianın proksimalidir. Tuberositas tibianın $2 \mathrm{~cm}$ inferomedialine yapılan mini insizyon sonrasında yaklaşık $45^{\circ}$ açıyla oyucuya takılan trokar medulla içerisine gönderilir (Şekil 1). Özel enjektör içerisine alacağımız aspirat miktarının \%20'si kadar antikoagülan sitrat dekstroz A içerir. Yaklaşık 60 cc otolog kemik iliği gönderilen kanüllü oyucuya kilitlenen özel şırıngayla aspire edilir (Şekil 2). Özel 


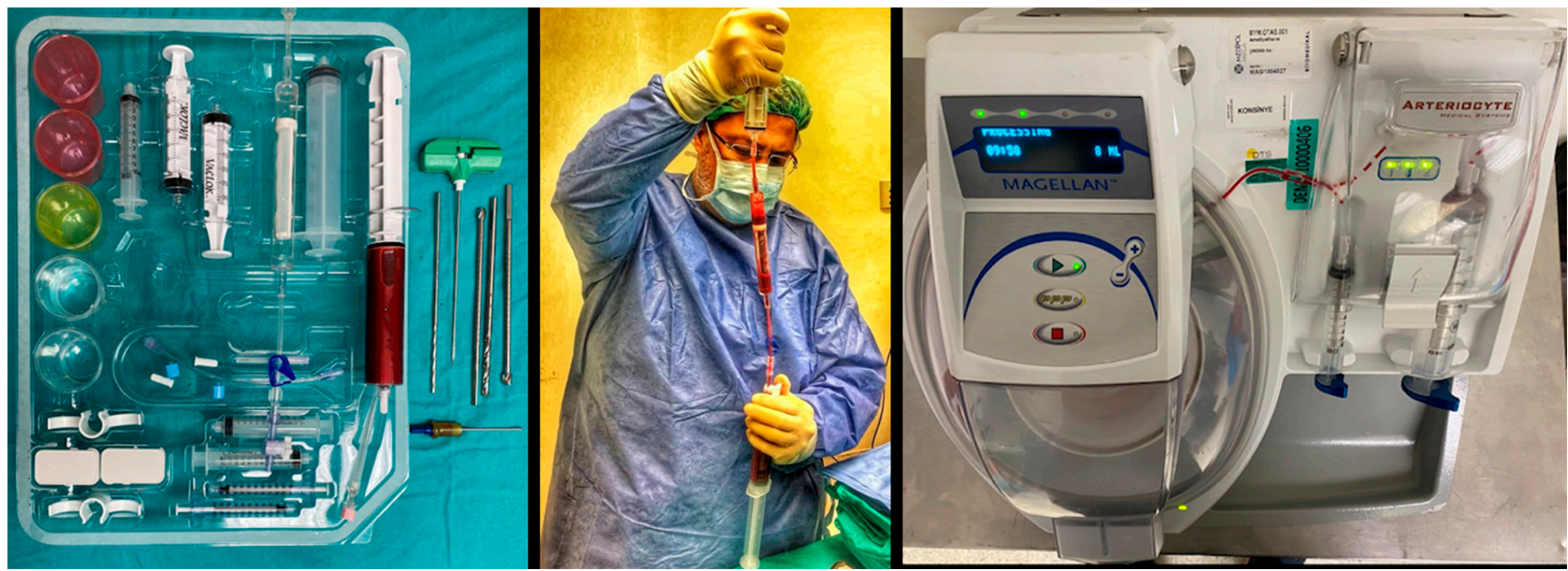

Şekil 3. Aspirat özel filtresinden bir kez süzülerek santrifüj cihazına aktarılacağı enjektöre nakledilir.

Tablo 1. Yaygın olarak kullanılan KiAK izolasyon sistemleri[22]

\begin{tabular}{|c|c|c|}
\hline İlacın ticari (müstahzar) ismi & Antikoagülan içeren & Santrifüj tipi \\
\hline Harvest SmartPrep 2 System & $\begin{array}{l}\text { İzolasyon şırıngası, şırıngaya eklenen heparin ve sitrat } \\
\text { dekstroz A ile önceden kaplanmıştır. }\end{array}$ & $\begin{array}{l}\text { ilik, santrifüjlenmeden önce } 200 \mu \mathrm{m} \text { filtre ile } \\
\text { önceden filtrelenmiştir. }\end{array}$ \\
\hline Biomet BioCue $\mathrm{TM}^{\mathrm{M}}$ & Sitrat dekstroz A & Ficoll yoğunluk gradyan santrifüj \\
\hline Arteriocyte Magellan ${ }^{\circledR}$ & $\begin{array}{l}\text { İzolasyon şırıngası, şırıngaya eklenen heparin ve sitrat } \\
\text { dekstroz A ile önceden kaplanmıştır. }\end{array}$ & $\begin{array}{l}\text { Illik, santrifüjlenmeden önce } 200 \mu \mathrm{m} \text { filtre ile } \\
\text { önceden filtrelenmiştir. }\end{array}$ \\
\hline Marrow Cellution ${ }^{\mathrm{TM}}$ & Antikoagülan gerekmez. & Santrifüj gerekmez. \\
\hline
\end{tabular}

KIAK, kemik iliği aspirasyon konsantresi (BMAC, bone-marrow-aspirate-concentrate).

filtresinden bir kez süzülerek santrifüj makinasına aktarilır (Şekil 3). Sonrasında değişik aspirasyon sistemleri tasarımlarına göre kök hücre elde etmek üzere cihazlara aktarılır (Tablo 1). ${ }^{[22]}$

Santrifüj makinasında yaklaşık $10 \mathrm{dk}$ işlemden geçen aspirattan mevcut MKH'yi istediğimiz hacimde ve konsantrasyonda elde ediyoruz. Kemik iliği aspirasyon materyali cihaza verildikten ve MKH ayrıştırma işlemi başlarken kor dekompresyon işlemine başlanır.

Supin yatırdığımız hastanın kalçasının altına bir yastık konulur; böylece $C$ kollu skopinin ve kalçanın rotasyonuyla iki düzlemde görüntü almamız mümkün oluyor. Tek taraflı FBO olgularında lateral dekubitte yatırılabilir. Büyük trokanter seviyesinde $3 \mathrm{~cm}$ longitudinal insizyon yapılır ve subkütan yağ dokusu gerilerek fasya lata ve vastus lateralis proksimal femurun lateral korteksine ulaşılana kadar disseke edilir. ${ }^{[16]}$ Takip eden adımda skopi kontrolü altında üzerinden oyma işlemi yapmamızı sağlayan kılavuz K-teli (Kirschner teli) skopi kontrolü altında, daha önce direkt grafi ve manyetik rezonans (MR) görüntüleme ile de tespit edilmiş olan osteonekrotik bölgeye gönderilir (Şekil 4).

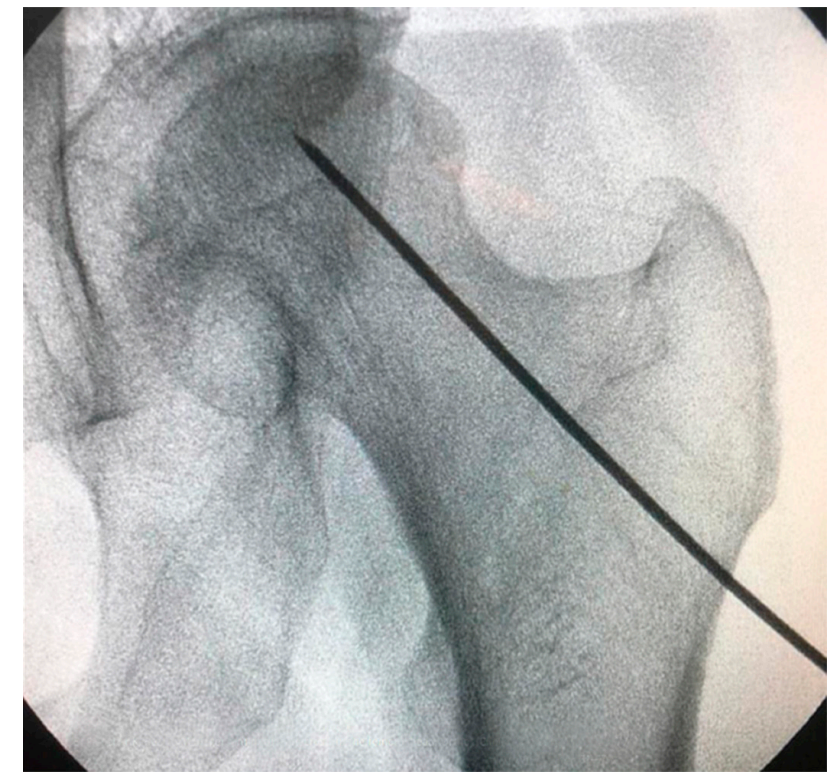

Şekil 4. Skopi kontrolü altında K-telinin lezyon bölgesindeki AP görünümü. ${ }^{[3]}$ 


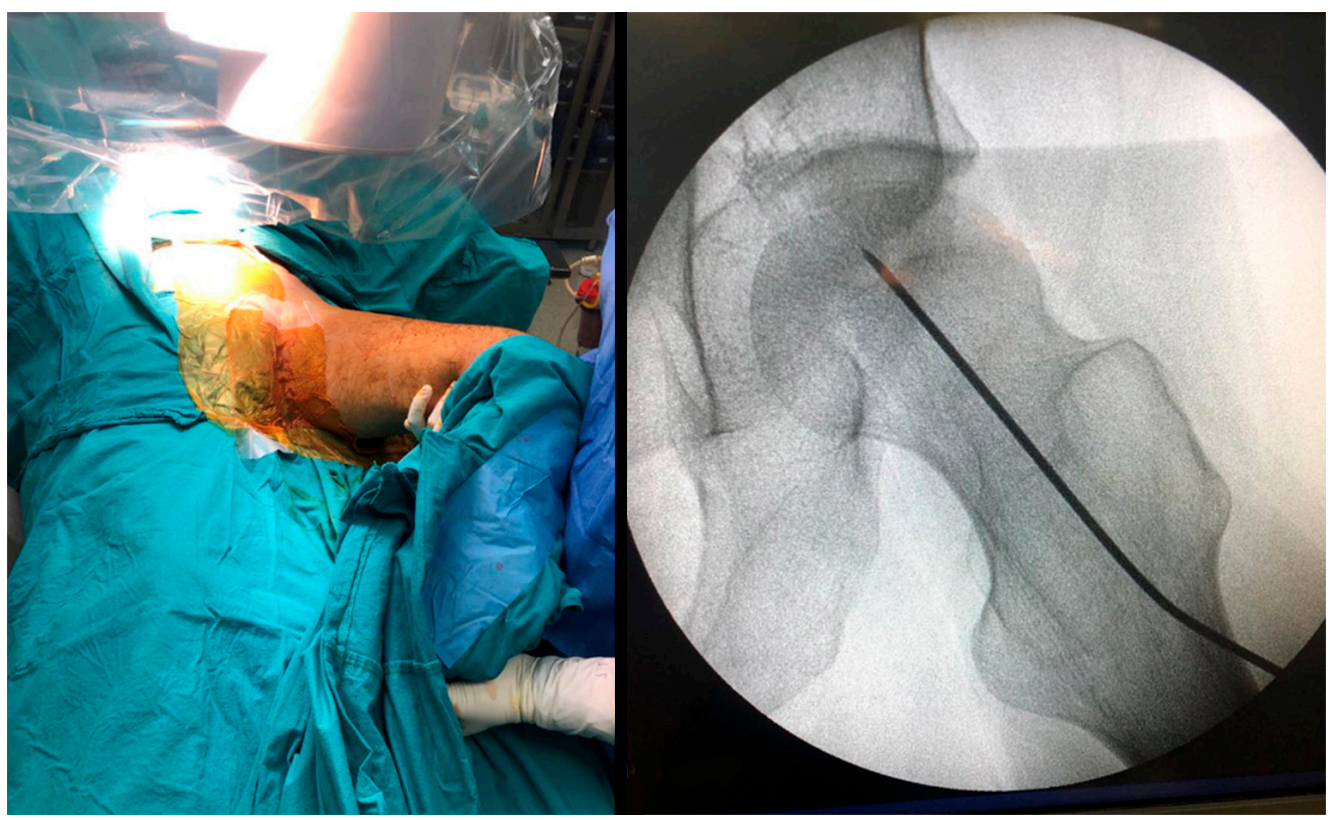

Şekil 5. Kalçanın kurbağa bacak pozisyonuna alınması ve gönderilen K-telinin lateral planda da lezyon bölgesinde olup olmadığının skopi görüntüsüyle kontrolü.

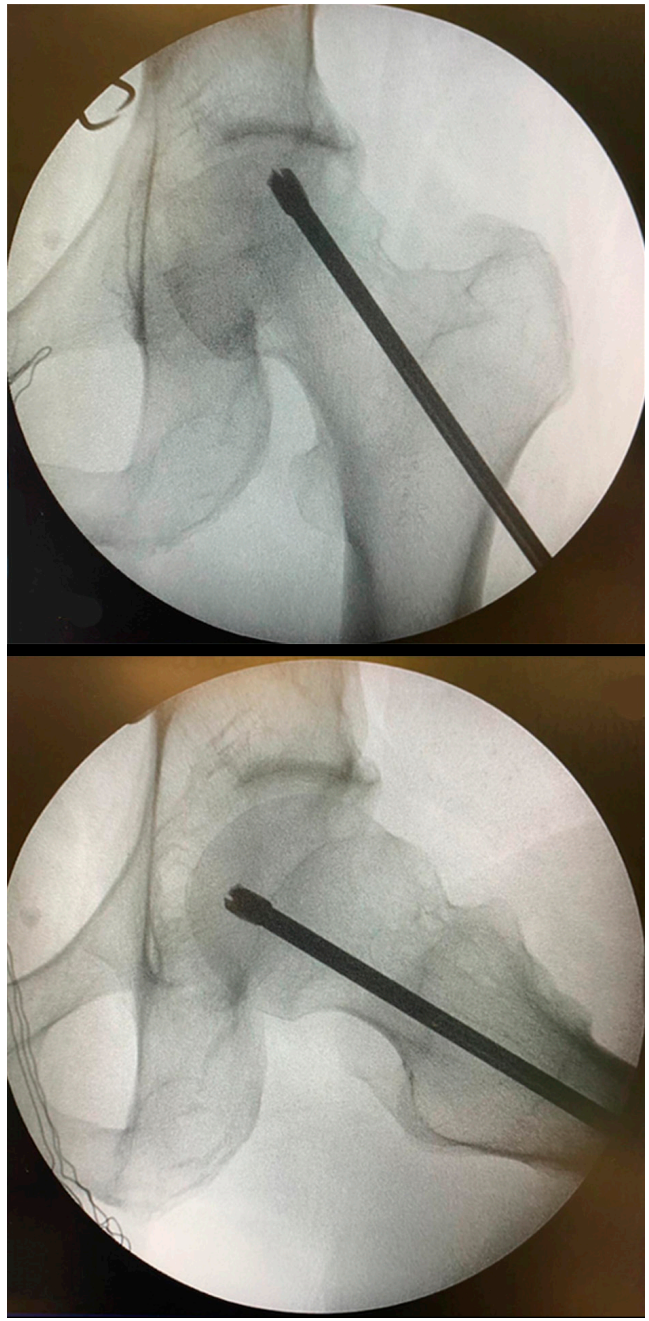

Şekil 6. K-teli üzerinden AVN lezyon bölgesine oyucunun gönderilmesi.

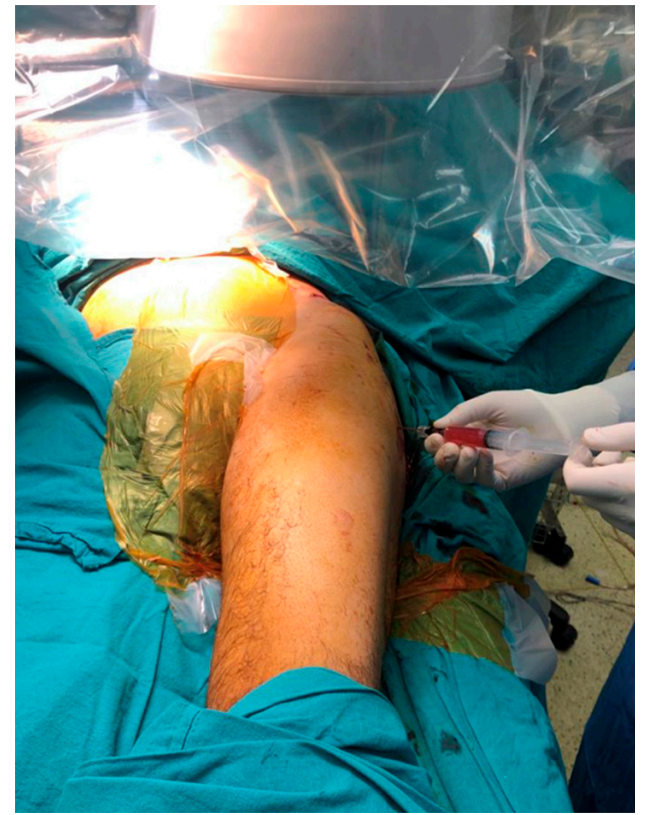

Şekil 7. Kök hücre süspansiyonunun AVN lezyon bölgesine enjekte edilmesi.
Daha sonra dış rotasyonla lateral pozisyonda da K-telinin osteonekrotik bölgede olup olmadığı kontrol edilir (Şekil 5). Takip eden aşamada oyucu ile K-teli üzerinden oyma işlemi gerçekleştirilir (Şekil 6).

Kor dekompresyon sonrasında uzun bir spinal iğne veya biyopsilerde kullandığımız trokar rehberliğinde skopi kontrolü altında kök hücre içeren süspansiyon enjekte edilir (Şekil 7). 


\section{KAYNAKLAR}

1. Moya-Angeler J, Gianakos AL, Villa JC, Ni A, Lane JM. Current concepts on osteonecrosis of the femoral head. World J Orthop 2015;6(8):590-601. Crossref

2. Mont MA, Zywiel MG, Marker DR, McGrath MS, Delanois RE. The natural history of untreated asymptomatic osteonecrosis of the femoral head: a systematic literature review. J Bone Joint Surg Am 2010;92(12):2165-70. Crossref

3. Plancher K, Razi A. Management of osteonecrosis of the femoral head. Orthop Clin North Am 1997;28(3):461-77. Crossref

4. Mont M, Cherian J, Sierra R, Jones LC, Lieberman JR. Nontraumatic osteonecrosis of the femoral head: where do we stand today? A ten-year update. J Bone Joint Surg Am 2015;97(19):1604-27. Crossref

5. Steinert AF, Rackwitz L, Gilbert F, Nöth U, Tuan RS. Concise review: the clinical application of mesenchymal stem cells for musculoskeletal regeneration: current status and perspectives. Stem Cells Transl Med 2012;1(3):237-47. Crossref

6. Gangji V, Hauzeur JP, Schoutens A, Hinsenkamp M, Appelboom T, Egrise D. Abnormalities in the replicative capacity of osteoblastic cells in the proximal femur of patients with osteonecrosis of the femoral head. J Rheumatol 2003;30(2):348-51. https://www.jrheum.org/ content $/ 30 / 2 / 348$.long

7. Hernigou P, Beaujean F. Treatment of osteonecrosis with autologous bone marrow grafting. Clin Orthop Relat Res 2002;405:14-23. Crossref

8. Tabatabaee RM, Saberi S, Parvizi J, Mortazavi SMJ, Farzan M. Combining concentrated autologous bone marrow stem cells injection with core decompression improves outcome for patients with early-stage osteonecrosis of the femoral head: a comparative study. J Arthroplasty 2015;30(9):11-5. Crossref

9. Daltro GC, Fortuna V, de Souza ES, Salles MM, Carreira AC, Meyer R, Freire SM, Borojevic R. Efficacy of autologous stem cell-based therapy for osteonecrosis of the femoral head in sickle cell disease: a five-year follow-up study. Stem Cell Res Ther 2015;6:110. Crossref

10. Sen RK, Tripathy SK, Aggarwal S, Marwaha N, Sharma RR, Khandelwal N. Early results of core decompression and autologous bone marrow mononuclear cells instillation in femoral head osteonecrosis: a randomized control study. J Arthroplasty 2012;27(5):679-86. Crossref

11. Zhao D, Cui D, Wang B, Tian F, Guo L, Yang L, Liu B, Yu X. Treatment of early stage osteonecrosis of the femoral head with autologous implantation of bone marrow-derived and cultured mesenchymal stem cells. Bone 2012;50(1):325-330. Crossref
12. Kristjánsson B, Honsawek S. Current perspectives in mesenchymal stem cell therapies for osteoarthritis. Stem Cells Int 2014;2014:194318. Crossref

13. Barry F, Murphy M. Mesenchymal stem cells in joint disease and repair. Nat Rev Rheumatol 2013;9(10):584-594. Crossref

14. Kebe C, Suzuki K. Mesenchymal stem cells for regenerative therapy: optimization of cell therapy protocols. Biomed Res Int 2014;2014:951512. Crossref

15. Crisostomo PR, Wang M, Wairiuko GM, Morrell ED, Terrell AM, Seshadri P, Nam UH, Meldrum DR. High passage number of stem cells adversely affects stem cell activation and myocardial protection. Shock 2006;26(6):575-80. Crossref

16. D’Ambrosi R, Biancardi E, Massari G, Ragone V, Facchini RM. Survival Analysis after Core Decompression in Association with Platelet-Rich Plasma, Mesenchymal Stem Cells, and Synthetic Bone Graft in Patients with Osteonecrosis of the Femoral Head. Joints 2018;6(1):16-22. Crossref

17. Enea D, Cecconi S, Calcagno S, Busilacchi A, Manzotti S, Gigante A. One-step cartilage repair in the knee: collagencovered microfracture and autologous bone marrow concentrate. A pilot study. Knee 2015:22(1);30-5. Crossref

18. Talathi NS, Kamath AF. Autologous stem cell implantation with core decompression for avascular necrosis of the femoral head. J Clin Orthop Trauma 2018;9(4):349-52. Crossref

19. Kang, JS, Suh YJ, Moon KH, Park JS, Roh TH, Park MH, Ryu DJ. Clinical efficiency of bone marrow mesenchymal stem cell implantation for osteonecrosis of the femoral head: a matched pair control study with simple core decompression. Stem Cell Res Ther 2018;9(1):274. Crossref

20. Hegde V, Shonuga O, Ellis S, Fragomen A, Kennedy J, Kudryashov V, Lane JM. A prospective comparison of 3 approved systems for autologous bone marrow concentration demonstrated nonequivalency in progenitor cell number and concentration. J Orthop Trauma 2014;28(10):591-8. Crossref

21. Shapiro SA, Kazmerchak SE, Heckman MG, Zubair AC, O'Connor MI. A prospective, single-blind, placebocontrolled trial of bone marrow aspirate concentrate for knee osteoarthritis. Am J Sports Med 2017;45(1):82-90. Crossref

22. Neubauer M, Jeyakumar $\mathrm{V}$, Muellner $\mathrm{T}$, Nehrer S. Bonemarrow-aspirate-concentrate for chondral defects: surgical techniques, clinical applications and basic science. Ann Joint 2018;3. Crossref 